\title{
Socioeconomic determinants of childhood obesity among primary school children in Guangzhou, China
}

\author{
Weijia Liu', Wei Liu', Rong Lin', Bai Li ${ }^{2}$ Miranda Pallan²*, K. K. Cheng ${ }^{2}$ and Peymane Adab²
}

\begin{abstract}
Background: Socioeconomic inequalities in childhood obesity prevalence differ according to a country's stage of nutrition transition. The aim of this study was to determine which socioeconomic factors influence inequalities in obesity prevalence in Chinese primary school children living in an urban setting.

Methods: We assessed obesity prevalence among 9917 children aged 5-12 years from a stratified random sample of 29 state-funded (residents) and private (migrants) schools in Guangzhou, China. Height and weight were objectively measured using standardised methods and overweight (+1 SD $<$ BMl-for-age $z$-score $\leq+2$ SD) and obesity (BMl-for-age $z$-score $>+2$ SD) were defined using the World Health Organisation reference 2007. Socioeconomic characteristics were ascertained through parental questionnaires. Generalised Linear Mixed Models with schools as a random effect were used to compare likelihood of overweight/obesity among children in private, with public schools, adjusting for child age and sex, maternal and paternal BMl and education level, and household per-capita income.
\end{abstract}

Results: The prevalence of overweight/obesity was $20.0 \%$ (95 \% Cl 19.1\%-20.9 \%) in resident compared with $14.3 \%$ (95\% Cl $13.0 \%-15.4 \%$ ) in migrant children. In the adjusted model, the odds of overweight/obesity remained higher among resident children (OR 1.36; 1.16-1.59), was higher in boys compared with girls (OR 2.56; 2.24-2.93), and increased with increasing age (OR 2.78; 1.95-3.97 in 11-12 vs 5-6 year olds), per-capita household income (OR 1.27; 1. 01-1.59 in highest vs lowest quartile) and maternal education (OR 1.51; 1.16-1.97 in highest vs lowest). Socioeconomic differences were most marked in older boys, and were only statistically significant in resident children.

Conclusions: The socioeconomic gradient for childhood obesity in China is the reverse of the patterns seen in countries at more advanced stages of the obesity epidemic. This presents an opportunity to intervene and prevent the onset of social inequalities that are likely to ensue with further economic development. The marked gender inequality in obesity needs further exploration.

Keywords: Socioeconomic status, Obesity, School children, China

\section{Background}

Globally, the increasing prevalence of obesity is a major public health problem in both the developed and the developing world, and is widely recognised as a key risk factor for a range of chronic diseases [1]. In China, the prevalence of overweight and obesity among school-aged

* Correspondence: M.J.Pallan@bham.ac.uk

${ }^{2}$ Public Health, Epidemiology and Biostatistics, Institute of Applied Health Research, College of Medical and Dental Sciences, University of Birmingham, Birmingham, UK

Full list of author information is available at the end of the article children has increased more rapidly and over a shorter time period than that seen in most Western countries $[2,3]$, with prevalence in some urban regions approaching those in developed countries $[4,5]$. Studies across China have also highlighted accelerating childhood obesity rates in rural areas, which face a double burden of over and undernutrition [6].

Developed countries which are at a more advanced stage of the obesity epidemic are facing a widening socioeconomic gap in childhood obesity [7]. Obesity prevalence is increasing among children in lower socioeconomic groups, whilst prevalence is stabilising or 
decreasing among children from more advantaged backgrounds [8]. However developing countries tend to have the reverse pattern, with higher childhood obesity prevalence among higher socioeconomic groups [9]. A few studies from China suggest that this trend may be changing in urban areas [10].

Rapid economic growth in China has resulted in major rural-urban migration [11]. Over 20 million people per year move out of rural areas [12], so that migrants now comprise a high proportion (up to $50 \%$ ) of the population in major urban cities in China [13]. In general, migrants tend to have lower levels of education and lower income [14]. To our knowledge, previous studies have not examined obesity rates among children from migrant families, compared to city residents in urban centres in China, nor examined whether the socioeconomic differences in childhood obesity are common to both groups. In China, there are two main types of primary schools. The majority of schools are state-funded public primary schools, which are managed by local government and funded mostly from taxation, with strict residency-based enrollment policies. The other are privately run primary schools owned by individuals or social organizations and funded mostly from tuition fees. Children of migrant families tend to attend the privately run, rather than state-funded public schools. This provides an opportunity to access children from a variety of backgrounds for assessing obesity patterns.

It is important to establish where China currently sits in terms of the obesity epidemic, in order to target preventive interventions where they are most needed, and also to prevent the onset of health inequalities that are widening in the developed world. Furthermore, it is important to disentangle which aspects of socioeconomic status (e.g. migrant status, income or parental education) are the main drivers of inequalities in childhood obesity. Previous studies have focused on differences in childhood obesity in urban versus rural areas, or across income groups within urban centres. Here, we estimated the prevalence of childhood obesity in a major city in China, comparing prevalence by migrant status and taking into account parental education and income.

\section{Methods}

\section{Participants and setting}

We conducted a cross-sectional analysis of data collected between April and June in 2014, of 9917 children aged 512 years from primary schools in Guangzhou, China. Guangzhou is a leading commercial southern Chinese city with a population of about 12.9 million, around a third of whom are migrant households [15]. There is public provision of schooling for primary school aged children whose parents are city residents, whereas children of migrant families attend private schools.
A multi-stage stratified cluster random sampling method was used to obtain a representative sample. Using a random number generator, five of the ten urban districts were first selected. Within each of the selected districts, schools were stratified by public (residents) or private (migrant) status, and six primary schools were randomly chosen, with a 2:1 ratio from each stratum. Within each school two classes per year group (from grade 1 to 5 ) were randomly selected, from which all pupils were invited to take part. Permission for the study was not obtained for one of the private schools in our sampling frame, leaving 29 participating schools.

\section{Measurements and questionnaires}

Informed consent for measurements was sought from the parents of all eligible children, and verbal assent was obtained from the children at the time of measurement. Anthropometric and blood pressure measurements and physical fitness assessments were undertaken by trained research staff, using standardised procedures and instruments. Parents were also asked to complete a questionnaire, detailing sociodemographic information and child lifestyle habits. In this paper, sociodemographic and anthropometric measurement data were used and are described in more detail below.

\section{Anthropometric measurements}

Height and weight were measured with subjects wearing light clothing and without shoes. Height was recorded to the nearest $0.1 \mathrm{~cm}$ with a TGZ type height tester (Dalian). Weight was measured to the nearest $0.1 \mathrm{~kg}$ using an electronic scale (JH-1993 T, weighing Apparatus Co.Ltd. Dalian). Body mass index (BMI; [weight (kg)]/[height $(\mathrm{m})]^{2}$ ), was calculated and BMI standard deviation scores (BMI z-score) were derived using the age (calculated by subtracting the date of birth from the date of examination) and sex specific WHO growth reference for schoolaged children [16], which were further classified as nonoverweight ( $\leq 1 \mathrm{SD})$, overweight (>1SD) and obese (>2SD).

\section{Parent questionnaires}

The parent questionnaire included information on parents' household income, number of people living in the household, and maternal and paternal educational level. Annual household income was divided by household size to obtain per-capita income, which was further categorised into quartiles $(<12,000 \mathrm{RMB}, 12,001-20,000 \mathrm{RMB}$, 20,001-34286RMB, $\geq 34287 R M B$ ). Parental education was categorised into low (primary and junior high school level), medium (senior high and vocational school level) or high (university level or higher). In addition, self-reported height and weight for each mother and father was obtained, from which parental BMI was derived. This was used to classify parents into the following weight status 
categories: normal weight $(\mathrm{BMI}<24)$, overweight $(\mathrm{BMI} \geq$ $24<28$ ), obese (BMI $\geq 28$ ), as defined by the guideline for prevention and control of overweight/obesity in Chinese adults [17].

\section{Statistical analysis}

Data were analysed using SPSS 21.0 statistical software package (SPSS Inc., Chicago, IL). Descriptive analysis was used to describe participant characteristics and the prevalence of overweight and obesity. Bivariate analysis was used to compare the prevalence of overweight/obesity by sociodemographic factors. In addition Pearson's correlation was used to examine the relationships between child and both maternal, and paternal BMI. Generalised linear mixed models were used to compare likelihood of overweight/obesity among children in private (migrant status), with public (resident status) schools, adjusting for child age and sex, maternal and paternal BMI and education level, and household per-capita income, with school as a random effect. We also described the prevalence of overweight/obesity by category of per-capita annual income for each age group, in boys compared with girls, and in migrant compared with non-migrant groups. Finally, we carried out sensitivity analyses: a) using the Chinese national reference norm introduced by the working group on obesity in China (WGOC), and b) the criteria introduced by international obesity taskforce (IOTF), instead of the WHO 2007 child growth standard. A 2-tailed P value less than 0.05 was considered statistically significant.

\section{Results}

\section{Characteristics of the study sample}

Among eligible children, $86.6 \%$ (9917/11445) agreed to take part in the study, resulting in a final sample of 9917 children aged 5-12 years, from 29 schools (9 private; 3057 children). The characteristics of the study population are summarised in Table 1. Boys were over-represented in the study sample, particularly in the migrant population (male:female ratio 1:42) and there was a higher proportion of older children (11-12 years) among migrant, compared with resident populations. Resident children were more likely to live in households with higher income and to have parents with higher levels of education, compared with migrants. Overall, $18.2 \%(95 \%$ CI $17.4 \%-19.0 \%)$ of all children were overweight or obese, with the proportion being higher among resident (20.0 \%; 95\%CI 19.1-20.9\%) compared with migrant (14.3\%; $95 \%$ CI 13.0-15.4 \%) children. Overweight/obesity was higher among fathers of resident compared to migrant children (41.5\% and $36.9 \%$ respectively), whereas the reverse was true for mothers (17.7 \% and $20.1 \%$ respectively).

\section{Socio-demographic factors associated with childhood} overweight/obesity

The relationship between socio-demographic factors and children's weight status is summarized in Table 2 . Overweight/obesity prevalence increased with increasing age $(9.1 \%$ in 5-6 years compared with $22.0 \%$ in 11-12 years) and was higher in boys (23.5 \%) compared with girls $(11.6 \%)$. There was also a statistically significant moderate relationship between child and both maternal and paternal BMI $(r=0.21$ and 0.18 respectively, $p<0.05$ ).

The likelihood of overweight/obesity increased with increasing quartile of household per-capita income and with increasing maternal education. There was no significant relationship between paternal education levels and child weight status. In the multilevel model adjusted for child age and sex, parental weight status, parental education level, and household per capita annual income, resident, compared with migrant children, had significantly higher odds of being overweight/obese.

\section{Relationship between income category and weight status by age group and migrant status}

Figure 1 shows the prevalence of overweight/obesity among younger and older boys and girls, according to annual per-capita household income. For all income groups, obesity prevalence was statistically significantly higher among boys compared with girls and in older compared with younger children. However, the sex disparity in obesity prevalence widened with increasing household income, and the age disparity was most marked among boys from the highest income households.

Figure 2 compares the relationship between household per-capita income and prevalence of overweight/obesity by migrant status in two age groups. Among children from resident households, there is a clear relationship between increasing household income and increased prevalence of obesity, particularly in the older age group $(p<0.05)$. However, there is no statistically significant relationship between household income and obesity prevalence among children from migrant households.

\section{Sensitivity analyses}

Repeating the analyses for factors associated with overweight/obesity, using the WGOC and IOTF instead of the WHO 2007 reference standard, did not alter the findings. The magnitude and direction of effect of all variables reported above remained similar to the main analysis, although the absolute values differed very slightly.

\section{Discussion}

We found that the prevalence of obesity among primary school children in an urban setting in China varied 
Table 1 Participant characteristics stratified by child's household registration

\begin{tabular}{|c|c|c|c|c|}
\hline \multirow[t]{2}{*}{ Characteristics } & \multirow{2}{*}{$\begin{array}{l}\text { Total } \\
\text { Mean } \pm \text { SD } \\
\text { or N (\%) }\end{array}$} & \multirow{2}{*}{$\begin{array}{l}\text { Migrant students } \\
\text { Mean } \pm \text { SD } \\
\text { or N (\%) }\end{array}$} & \multicolumn{2}{|c|}{$\begin{array}{l}\text { Non-Migrant (Resident) } \\
\text { students }\end{array}$} \\
\hline & & & $\begin{array}{l}\text { Mean } \pm S D \\
\text { or N (\%) }\end{array}$ & $P$ value \\
\hline $\mathrm{N}$ & 9917 & $3057(30.8)$ & $6860(69.2)$ & \\
\hline Age (years) & $9.24 \pm 1.50$ & $9.27 \pm 1.60$ & $9.24 \pm 1.45$ & 0.243 \\
\hline BMI z-score & $-0.19 \pm 1.31$ & $-0.29 \pm 1.22$ & $-0.14 \pm 1.34$ & $<0.001$ \\
\hline \multicolumn{5}{|l|}{ Gender } \\
\hline Boys & $5529(55.8)$ & $1792(58.6)$ & $3737(54.5)$ & \multirow[t]{2}{*}{$<0.001$} \\
\hline Girls & $4388(44.2)$ & $1265(41.4)$ & $3123(45.5)$ & \\
\hline \multicolumn{5}{|l|}{ Age } \\
\hline $5-6$ years & $657(6.6)$ & $242(7.9)$ & $415(6.0)$ & \multirow[t]{4}{*}{$<0.001$} \\
\hline $7-8$ years & $3784(38.2)$ & $1116(36.5)$ & $2668(38.9)$ & \\
\hline $9-10$ years & $3942(39.7)$ & $1178(38.5)$ & $2764(40.3)$ & \\
\hline 11-12years & $1534(15.5)$ & $521(17.0)$ & $1013(14.8)$ & \\
\hline \multicolumn{5}{|l|}{ Level of yearly income (per-capital) } \\
\hline 1st quartile ( $\leq 12000 \mathrm{RMB})$ & $1463(17.3)$ & $669(27.4)$ & $772(13.0)$ & \multirow[t]{4}{*}{$<0.00$} \\
\hline 2nd quartile (12001-20000 RMB) & $2327(27.6)$ & $882(34.9)$ & $1445(24.4)$ & \\
\hline 3rd quartile (20001-34286 RMB) & $2545(30.2)$ & $609(24.1)$ & $1936(32.7)$ & \\
\hline 4th quartile ( $\geq 34287 \mathrm{RMB}$ ) & $2105(24.9)$ & $342(13.5)$ & $1763(29.8)$ & \\
\hline \multicolumn{5}{|l|}{ Father's education } \\
\hline Primary school and junior high school & 3919(42.6) & $1858(67.9)$ & $2061(31.9)$ & \multirow[t]{3}{*}{$<0.001$} \\
\hline Senior high school and vocational school & $4006(43.5)$ & $783(28.6)$ & $3223(49.8)$ & \\
\hline University and above & $1281(13.9)$ & $96(3.5)$ & $1185(18.3)$ & \\
\hline \multicolumn{5}{|l|}{ Mother's education } \\
\hline Primary school and junior high school & $4608(50.0)$ & $2103(76.9)$ & 2505 (38.6) & \multirow[t]{3}{*}{$<0.00$} \\
\hline Senior high school and vocational school & $3551(38.5)$ & $565(20.7)$ & $2986(46.1)$ & \\
\hline University and above & $1057(11.5)$ & $66(2.4)$ & $991(15.3)$ & \\
\hline \multicolumn{5}{|l|}{ Child Weight status } \\
\hline Normal weight & $8112(81.8)$ & $2621(85.7)$ & $5491(80.0)$ & \multirow[t]{3}{*}{$<0.001$} \\
\hline Overweight & $1126(11.4)$ & $290(9.5)$ & $836(12.2)$ & \\
\hline Obese & $679(6.8)$ & $146(4.8)$ & $534(7.8)$ & \\
\hline \multicolumn{5}{|l|}{ Father's Weight status } \\
\hline Normal weight & $5037(59.8)$ & $1534(63.0)$ & $3503(58.5)$ & \multirow[t]{3}{*}{0.001} \\
\hline Overweight & $2853(33.9)$ & $764(31.4)$ & $2089(34.9)$ & \\
\hline Obese & $529(6.3)$ & $135(5.5)$ & $394(6.6)$ & \\
\hline \multicolumn{5}{|l|}{ Mother's Weight status } \\
\hline Normal weight & 7034 (81.6) & 1975 (79.9) & $5059(82.3)$ & \multirow[t]{3}{*}{0.003} \\
\hline Overweight & $1394(16.2)$ & $425(17.2)$ & 969 (15.8) & \\
\hline Obese & $190(2.2)$ & $72(2.9)$ & $118(1.9)$ & \\
\hline
\end{tabular}

Note: There are some missing vales in the analysis variables above. Analysis Variables: Level of yearly income (1477); Father's education (711); Mother's education (701); Father's weight status (1498); Mother's occupation (1299). $1^{\text {st }}$ quartile: $1 \%-25 \%$ percentiles, $2^{\text {nd }}$ quartile: $26 \%-50 \%$ percentiles, $3^{\text {rd }}$ quartile: $51 \%-75 \%$ percentiles, $4^{\text {th }}$ quartile: $76 \%-100 \%$ percentiles

greatly according to sociodemographic characteristics. Overall, rates were highest among boys compared with girls, and increased with age, household per-capita income and higher maternal education levels. Social inequalities in obesity were particularly seen in boys, and widened with age. To our knowledge, this is the first study that has examined childhood obesity prevalence in urban migrants and contrasted this with prevalence in 
Table 2 Generalized linear mixed model analysis of socioeconomic factors correlates of overweight and obesity among school children in Guangzhou, China

\begin{tabular}{|c|c|c|c|}
\hline \multirow[t]{2}{*}{ Characteristics } & \multirow{2}{*}{$\begin{array}{l}\text { Overweight or obese } \\
\text { Number (\%) }\end{array}$} & \multicolumn{2}{|c|}{$\underline{\text { Likelihood of overweight/obesity }}$} \\
\hline & & Crude OR (95 \% Cl) & Adjusted OR (95\% Cl) \\
\hline \multicolumn{4}{|l|}{ Gender } \\
\hline Girls & $4388(11.6)^{* *}$ & Reference & Reference \\
\hline Boys & $5529(23.5)$ & $2.40(2.15-2.69)^{* *}$ & $2.56(2.24-2.93)^{* *}$ \\
\hline \multicolumn{4}{|l|}{ Age } \\
\hline $5-6$ years & $657(9.1)^{* *}$ & Reference & Reference \\
\hline $7-8$ years & $3784(16.2)$ & $1.88(1.42-2.49)^{* *}$ & $1.95(1.39-2.74)^{* *}$ \\
\hline $9-10$ years & $3942(20.1)$ & $2.46(1.86-3.25)^{* *}$ & $2.59(1.85-3.62)^{* *}$ \\
\hline $11-12$ years & $1534(22.0)$ & $2.77(2.06-3.71)^{* *}$ & $2.78(1.95-3.97)^{* *}$ \\
\hline \multicolumn{4}{|l|}{ Household per-capita annual income } \\
\hline 1st quartile ( $\leq 12000 \mathrm{RMB})$ & $1463(14.8)^{*}$ & Reference & Reference \\
\hline 2nd quartile (12001-20000 RMB) & $2327(16.3)$ & $1.07(0.89-1.28)$ & $1.01(0.82-1.24)$ \\
\hline 3rd quartile (20001-34286 RMB) & $2545(19.1)$ & $1.22(1.02-1.46)^{*}$ & $1.21(0.99-1.49)^{*}$ \\
\hline 4th quartile ( $\geq 34287$ RMB) & $2105(21.4)$ & $1.34(1.11-1.63)^{*}$ & $1.27(1.01-1.59)^{*}$ \\
\hline \multicolumn{4}{|l|}{ Father's education } \\
\hline Primary school and junior high school & $3919(16.2)$ & Reference & Reference \\
\hline Senior high school and vocational & $4006(20.0)$ & $1.13(0.99-1.27)$ & $1.11(0.95-1.31)$ \\
\hline University and above & $1281(19.8)$ & $1.01(0.84-1.21)$ & $0.89(0.69-1.16)$ \\
\hline \multicolumn{4}{|l|}{ Mother's education } \\
\hline Primary school and junior high school & $4608(16.0)^{*}$ & Reference & Reference \\
\hline Senior high school and vocational & $3551(20.1)$ & $1.19(1.05-1.35)^{*}$ & $1.21(1.03-1.43)^{*}$ \\
\hline University and above & $1057(22.8)$ & $1.32(1.10-1.59)^{*}$ & $1.51(1.16-1.97)^{*}$ \\
\hline \multicolumn{4}{|l|}{ Father's weight status } \\
\hline Non-overweight & $5037(14.9)^{* *}$ & Reference & Reference \\
\hline Overweight & $2853(22.9)$ & $1.67(1.48-1.87)^{* *}$ & $1.63(1.43-1.85)^{* *}$ \\
\hline Obese & $529(31.2)$ & $2.54(2.08-3.11)^{* *}$ & $2.48(1.98-3.11)^{* *}$ \\
\hline \multicolumn{4}{|l|}{ Mother's weight status } \\
\hline Non-overweight & $7034(15.9)^{* *}$ & Reference & Reference \\
\hline Overweight & $1394(29.3)$ & $2.27(1.98-2.59){ }^{*}$ & $2.41(2.07-2.80)^{* *}$ \\
\hline Obese & $190(30.5)$ & $2.56(1.86-3.52)^{* *}$ & $2.51(1.72-3.67)^{* *}$ \\
\hline \multicolumn{4}{|l|}{ Type of school } \\
\hline Private (migrants) & $3057(14.3)^{* *}$ & Reference & Reference \\
\hline Public (residents) & $6860(20.0)$ & $1.48(1.19-1.83)^{* *}$ & $1.36(1.16-1.59)^{* *}$ \\
\hline
\end{tabular}

Note: Generalised Linear Mixed Models were used for multivariateanalyses, adjusted model includes all social-demographic factors above, and school as a random effect. Dependent variable: children were categorized into two groups (overweight/obese and non-overweight) using WHO 2007. OR, odds ratio; $\mathrm{Cl}$, confidence interval. $1^{\text {st }}$ quartile: $1 \%-25 \%$ percentiles, $2^{\text {nd }}$ quartile: $26 \%-50 \%$ percentiles, $3^{\text {rd }}$ quartile: $51 \%-75 \%$ percentiles, $4^{\text {th }}$ quartile: $76 \%-100 \%$ percentiles. ${ }^{*} p<0.05,{ }^{* *} p<0.001$

urban residents. In the adjusted models, household income, maternal education, and migrant status were all independently associated with obesity. However, among children from migrant households, overweight rates did not differ much between income groups, suggesting that social inequalities have not yet emerged within migrant families.
The overall prevalence of obesity in primary school children is similar to those reported in other studies in urban centres in China $[18,19]$ and the gender $[20,21]$ and socioeconomic [20] disparity are also in keeping with previous studies. Overweight/obesity rates among preadolescent boys (aged 9-12 years) in the highest income households were over $34.1 \%$, which is similar to 


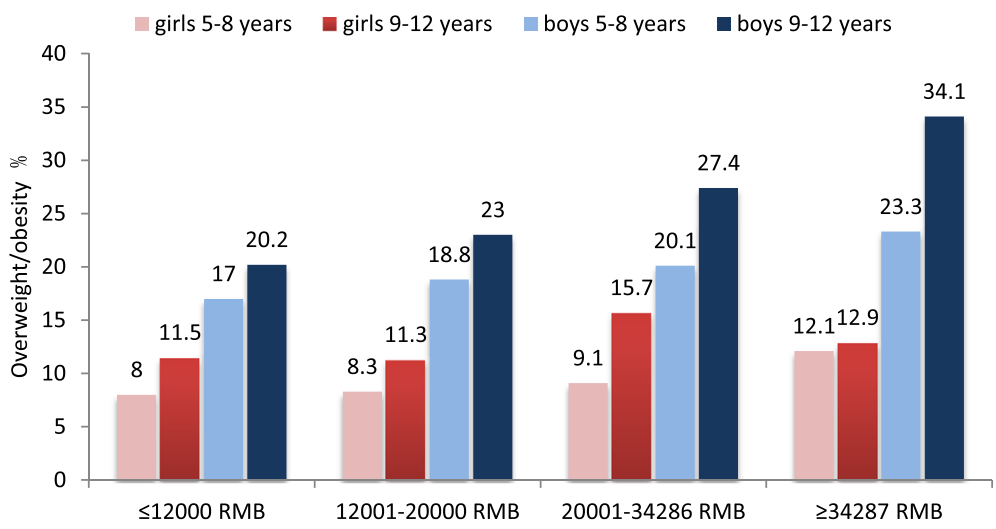

Fig. 1 Prevalence of overweight/obesity among younger (age 5-8 years) and older (age 9-12 years) Chinese primary school boys and girls according to quartiles of per capita household income

the prevalence in many developed countries [22-25]. In contrast, the prevalence of obesity in pre-adolescent girls $(\sim 12 \%)$, was lower than rates in the West and did not differ as much between high and low income groups. The positive socioeconomic gradient in obesity among boys and girls is opposite to that observed in developed countries, and may be due to the current stage of economic development in China [20]. Affordability of high energy dense foods and access to more sedentary modes of transport and leisure pursuits is likely to be greater among higher income families. We found that independently of household income, higher maternal education was also associated with higher rates of obesity. This is contrary to findings in the West, where higher parental education is associated with lower childhood obesity [26, 27] and suggests that factors other than purchasing power also contribute to the socioeconomic gradient. Maternal education has been shown to be associated with better child nutrition and growth internationally, with lower obesity in developed countries, and with lower rates of stunting and malnutrition in rural China [28].

The marked gender difference in obesity also contrasts with the pattern observed in most other countries [29]. The reason for lower rates of obesity among girls is not clear, but may be due to societal norms of ideal body image for girls $[30,31]$ or a cultural preference for boys [32], leading to overfeeding. The latter may also explain the higher male to female ratio in school pupils observed in this study.

Including a large representative sample of children in a typical urban setting in China with objective measures of adiposity and adjustment for parental weight status are strengths of this study. Furthermore, use of more than one measure of socioeconomic status and comparison of migrant with resident households within the same setting offer novel insights. The main limitation is the cross-sectional nature, which does not allow us to infer causal relationships. Furthermore the measures of family income, parents' education and parents' weight status

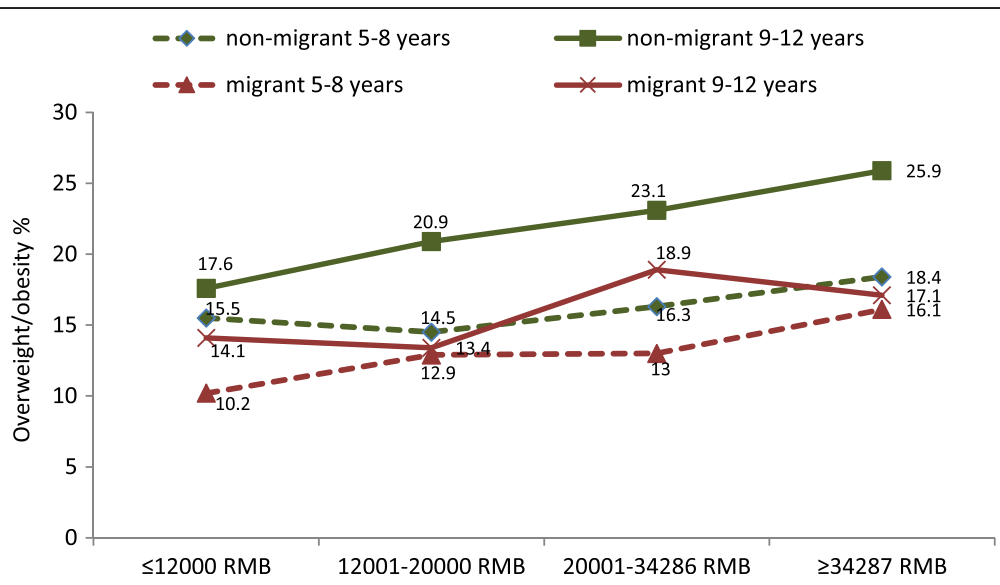

Fig. 2 Prevalence of overweight/obesity among younger (age 5-8 years) and older (age 9-12 years) resident and migrant Chinese primary school children according to quartiles of per capita household income 
were all based on self-report, which may reduce their validity. We also did not have data on duration of residency in Guangzhou among migrant families, and so were not able to examine differences according to time since migration.

\section{Conclusions}

Our findings suggest that contrary to findings in some previous studies [6], a reversal in the socioeconomic gradient for childhood obesity has not yet occurred in our study population. There is an opportunity to apply lessons from countries at more advanced stage of the obesity epidemic to prevent the shift in obesity patterns and subsequent social inequalities that are likely to ensue with further economic development. Rural-urban migrants, and those with lower household income and education have lower rates of obesity, which could be maintained with the introduction of government food and physical activity policies [33-35]. The marked gender inequality in obesity needs further exploration.

\section{Abbreviations}

$\mathrm{Cl}$, confidence intervals; $\mathrm{OR}$, odds ratio; SD, standard deviation; $\mathrm{BMI}$, body mass index; WGOC, working group on obesity in China; IOTF, international obesity taskforce; WHO, world health organization

\section{Acknowledgements}

The authors gratefully acknowledge the contribution of Yuexiu, Haizhu, Liwan, Luogang and Nansha Education Bureau and 29 elementary schools.

\section{Funding}

The data used for this analysis came from a study funded by the Guangzhou Medical Foundation (20131A031001)

\section{Availability of data and material}

Data sharing: Participant level data are available from the authors on request.

\section{Authors' contributions}

WJL is the Principal Investigator for the study and oversaw all aspects of data collection and analysis, with advice from PA and MP. WJL wrote the first draft of the paper, with contribution from PA. All authors contributed to study design and conduct of the study, and contributed to the final manuscript. All authors have read and approved the final manuscript.

\section{Competing interests}

The authors declare that they have no competing interests.

\section{Ethics approval and consent to participate}

Permissions to conduct the study were granted by the Guangzhou Departments of Education and Health. The study was approved by the Ethical Committee of Guangzhou Center for Disease Control and Prevention and the University of Birmingham Ethics Committee (reference ERN_13-1519). Informed consent for measurements was sought from the parents of all eligible children, and verbal assent was obtained from the children at the time of measurement.

\section{Author details}

${ }^{1}$ Faculty of School Health, Guangzhou Centre for Disease Control and Prevention, Guangzhou, China. ${ }^{2}$ Public Health, Epidemiology and Biostatistics, Institute of Applied Health Research, College of Medical and Dental Sciences, University of Birmingham, Birmingham, UK.

Received: 2 January 2016 Accepted: 19 May 2016 Published online: 08 June 2016

\section{References}

1. Ebbeling CB, Pawlak DB, Ludwig DS. Childhood obesity: public-health crisis, common sense cure. Lancet. 2002;360(9331):473-82.

2. Ji CY, Chen TJ. Empirical changes in the prevalence of overweight and obesity among Chinese students from 1985 to 2010 and corresponding preventive strategies. Biomed Environ Sci. 2013;26(1):1-12.

3. Wang Y, Lobstein T. Worldwide trends in childhood overweight and obesity. Int J Pediatr Obes. 2006;1 (1):11-25.

4. Ji CY, Cheng TO. Prevalence and geographic distribution of childhood obesity in China in 2005. Int J Cardiol. 2008;131(1):1-8.

5. Ji CY. Report on childhood obesity in China (4) prevalence and trends of overweight and obesity in Chinese urban school-age children and adolescents, 1985-2000. Biomed Environ Sci. 2007;20(1):1-10.

6. Dearth-Wesley T, Wang H, Popkin BM. Under- and overnutrition dynamics in Chinese children and adults (1991-2004). Eur J Clin Nutr. 2007;62(11):1302-7.

7. Stamatakis E, Zaninotto P, Falaschetti E, Mindell J, Head J. Time trends in childhood and adolescent obesity in England from 1995 to 2007 and projections of prevalence to 2015. J Epidemiol Community Health. 2010;64(2):167-74.

8. Frederick CB, Snellman K, Putnam RD. Increasing socioeconomic disparities in adolescent obesity. Proc Natl Acad Sci U S A. 2014;111(4):1338-42.

9. Wang Y. Cross-national comparison of childhood obesity: the epidemic and the relationship between obesity and socioeconomic status. Int J Epidemiol. 2001;30(5):1129-36.

10. Jones-Smith JC, Gordon-Larsen P, Siddiqi A, Popkin BM. Emerging disparities in overweight by educational attainment in Chinese adults (1989-2006). Int J Obes (Lond). 2012;36(6):866-75.

11. Chan KW, Zhang L. The Hukou System and Rural-urban Migration in China: Processes and Changes. China Quarterly. 1999;160:818-55.

12. Dunford M, Liu W. The geographical transformation of China. Oxford: Routledge; 2014.

13. Lin $B N$, Song $X Q$, Zuo LD, Ling L. Problems and Countermeasures to the Health Insurance of Migrants in Guangzhou. Med Soc. 2013;6:020.

14. Tang S, Meng Q, Chen L, Bekedam H, Evans T, Whitehead M. Tackling the challenges to health equity in China. The Lancet 2008;372(9648):1493-501.

15. Li S-M, Zhu Y. Residential mobility within Guangzhou city, China, 1990-2010: local residents versus migrants. Eurasian Geography Economics. 2014:55(4):313-32

16. de Onis M, Onyango AW, Borghi E, Siyam A, Nishida C, Siekmann J. Development of a WHO growth reference for school-aged children and adolescents. Bull World Health Organ. 2007;85(9):660-7.

17. Division of Disease Control, Ministry of Health of the People's Republic of China. The guideline for prevention and control of overweight and obesity in Chinese adults [M]. Beijing: People's Medical Publishing House; 2006. in Chinese.

18. Yu Z, Han S, Chu J, Xu Z, Zhu C, Guo X. Trends in overweight and obesity among children and adolescents in China from 1981 to 2010: a meta-analysis. PLoS One. 2012;7(12):e51949.

19. Li B, Adab P, Cheng KK. Family and neighborhood correlates of overweight and obesogenic behaviors among Chinese children. Int J Behav Med. 2014;21(4):700-9.

20. He W, James SA, Merli MG, Zheng H. An increasing socioeconomic gap in childhood overweight and obesity in China. Am J Public Health. 2014; 104(1):e14-22

21. Song $\mathrm{Y}$, Wang $\mathrm{H}-\mathrm{J}, \mathrm{Ma} J$, Wang $\mathrm{Z}$. Secular Trends of Obesity Prevalence in Urban Chinese Children from 1985 to 2010: Gender Disparity. PLoS One. 2013;8(1):e53069.

22. National Child Measurement Programme (NCMP). utrition and healthy weight regional events 2013. 2014.

23. Shields M, Tremblay MS. Canadian childhood obesity estimates based on WHO, IOTF and CDC cut-points. Int J Pediatr Obes. 2010;5(3):265-73.

24. Pigeot I, Barba G, Chadjigeorgiou C, de Henauw S, Kourides Y, Lissner L, Marild S, Pohlabeln H, Russo P, Tornaritis M, Veidebaum T, Wawro N, Siani A. Prevalence and determinants of childhood overweight and obesity in European countries: pooled analysis of the existing surveys within the IDEFICS Consortium. Int J Obes (Lond). 2009;33:1103-10.

25. Ogden C, Carroll MD, Kit BK, Flegal KM. Prevalence of Obesity and Trends in Body Mass Index Among US Children and Adolescents, 1999-2010. JAMA. 2012;307:483-90.

26. Lamerz A, Kuepper-Nybelen J, Wehle C, et al. Social class, parental education, and obesity prevalence in a study of six-year-old children in Germany. Int J Obes (Lond). 2005;29(4):373-80. 
27. Connelly R. Drivers of unhealthy weight in childhood: analysis of the Millennium Cohort Study. Edinburgh: Scottish Government Social Research; 2011.

28. Lakshman R, Zhang J, Zhang J, et al. Higher maternal education is associated with favourable growth of young children in different countries. J Epidemiol Community Health. 2013;67(7):595-602.

29. Kanter R, Caballero B. Global gender disparities in obesity: a review. Adv Nutr. 2012;3(4):491-8.

30. Luo Y, Parish WL, Laumann EO. A population-based study of body image concerns among urban Chinese adults. Body Image. 2005;2(4):333-45.

31. Xie B, Chou CP, Spruijt-Metz D, et al. Effects of perceived peer isolation and social support availability on the relationship between body mass index and depressive symptoms. Int J Obes (Lond). 2005;29(9):1137-43.

32. Eklund L. Rethinking Son Preference-Gender, Population Dynamics and Social Change in the People's Republic of China. Lund University; 2011. http://lup.lub.lu.se/record/1950819. Accessed 7 Jun 2016.

33. Gortmaker SL, Swinburn BA, Levy D, et al. Changing the future of obesity: science, policy, and action. The Lancet. 2011;378(9793):838-47

34. Lobstein T, Jackson-Leach R, Moodie ML, et al. Child and adolescent obesity: part of a bigger picture. The Lancet 2015;385(9986): 2510-20

35. Hawkes C, Smith TG, Jewell J, et al. Smart food policies for obesity prevention. The Lancet 2015:385(9985):2410-21.

Submit your next manuscript to BioMed Central and we will help you at every step:

- We accept pre-submission inquiries

- Our selector tool helps you to find the most relevant journal

- We provide round the clock customer support

- Convenient online submission

- Thorough peer review

- Inclusion in PubMed and all major indexing services

- Maximum visibility for your research

Submit your manuscript at www.biomedcentral.com/submit
) Biomed Central 